ORIGINAL RESEARCH PAPER

\title{
ASSESSMENT OF THE ACRYLAMIDE LEVEL OF CEREAL-BASED PRODUCTS FROM ROMANIA MARKET IN ACCORDANCE WITH COMMISSION REGULATION (EU) 2017/2158
}

\author{
ADRIANA LAURA MIHAI, MIOARA NEGOIȚǍ*, GABRIELA-ANDREEA HORNEȚ
}

National Research \& Development Institute for Food Bioresources, IBA Bucharest, 6 Dinu Vintilă Street, District 2, 021102, Bucharest, Romania

*corresponding author: mioaranegoita@yahoo.com

Received on 27 March 2020

Revised on 1 May 2020

\begin{abstract}
This study reports the acrylamide (AA) content of some cereal-based products purchased from different Romanian suppliers. The AA level was determined by using gas chromatography tandem mass spectrometry (GC-MS/MS) in SRM mode. The analytical method was characterized by a high degree of sensitivity (limit of detection $(\mathrm{LOD})=1.23 \mu \mathrm{g} / \mathrm{kg}$, and limit of quantification $(\mathrm{LOQ})=3.70$ $\mu \mathrm{g} / \mathrm{kg})$.

A total of 46 food samples of bread, biscuits, and similar products (doughnuts, cakes, cookies etc.) were analysed. The results showed that the AA level varied between food samples, for soft bread $(5.63-85.05 \mu \mathrm{g} / \mathrm{kg})$, biscuits $(8.55-548.80$ $\mu \mathrm{g} / \mathrm{kg})$, crackers $(13.92-167.58 \mu \mathrm{g} / \mathrm{kg})$ and for similar products $(12.57-99.01$ $\mu \mathrm{g} / \mathrm{kg}$ ) which were lower than the benchmark levels set by the Commission Regulation (EU) $2017 / 2158$. The highest AA content $(548.80 \mu \mathrm{g} / \mathrm{kg})$ was found for biscuits, while the lowest AA content $(5.63 \mu \mathrm{g} / \mathrm{kg})$ was obtained for wheatbased bread. From the analysed products, 4 biscuit samples exceeded the benchmark levels of $350 \mu \mathrm{g} / \mathrm{kg}$ established by European Union.
\end{abstract}

Keywords: acrylamide, biscuits, bread, cereal-based products, GC-MS/MS

\section{Introduction}

Cereal-based products are an important source of fibres in the diet in many countries, contributing to human health. From the cereal products, bakery products are the most important category. During the baking process, the Maillard reaction takes place by interaction between reducing sugars and asparagine, an amino acid found in plant-based products, like this being formed acrylamide (AA). AA is a

https://doi.org/10.35219/foodtechnology.2020.1.06 
chemical compound found when carbohydrates and protein-rich foods are subjected to temperatures higher than $120^{\circ} \mathrm{C}$ and in low moisture conditions.

Since 2002, when it was discovered in food, many studies have been made to determine the human exposure to AA and its effect on human health. AA was categorized as a member of the group 2A substances by the International Agency for Research on Cancer (IARC, 1994), which means that is probably carcinogenic to humans. AA poses a serious risk to humans having cytotoxic effect producing cellular oxidative stress, apoptotic, having anti-proliferative activity (Kacar et al., 2019), affecting the reproductive system (AL Karim et al., 2015; Matoso et al., 2019). Due to this impact on human health, EFSA experts established a benchmark dose lower confidence limit $\left(\mathrm{BMDL}_{10}\right)$ of $0.17 \mathrm{mg} / \mathrm{kg}$ body weight (b.w.)/day for tumours incidence and $0.43 \mathrm{mg} / \mathrm{kg}$ b.w./day, respectively for other potential adverse consequences, as neurological changes and effects on reproductive system. It was also set a margin of exposure (MOE) which indicate the level of health concern, these values varying between 425 for average adult consumer and down to 50 for high consuming toddlers (EFSA, 2015). The exposure of young people is higher than that of adults, in particular, the exposure of toddlers is in the highest range. In addition, The Joint FAO/WHO Expert Committee on Food Additives stated that children dietary exposure to AA were about twice than those of adult consumers, when expressed on a b.w. basis (FAO/WHO, 2011).

It was reported that the mean AA exposure in Europe was estimated to range from 0.4 to $0.6 \mu \mathrm{g} / \mathrm{kg}$ b.w./day for adults, $0.4-0.9 \mu \mathrm{g} / \mathrm{kg}$ b.w./day for adolescents, $0.5-$ $1.3 \mu \mathrm{g} / \mathrm{kg}$ b.w./day for infants and $0.9-1.9 \mu \mathrm{g} / \mathrm{kg}$ b.w. per day for toddlers (EFSA, 2015).

Based on the monitored results, the European Commission has implemented the Regulation 2017/2158 to establish mitigation measures and benchmark levels for the reduction of the presence of acrylamide in food. These benchmark levels are not safety values but performance indicators used to verify the effectiveness of the mitigation measures applied for AA reduction in different food. It should be established as low as reasonably achievable with the application of all relevant mitigation measures.

Also, the European food and drink industries together with national authorities of the European Union proposed a toolbox, in which was presented the pathways of acrylamide formation and recommended some mitigation strategies (Food Drink Europe, 2019).

The AA level of cereal-based products is influenced by the type of cereal flour used (refined/wholegrain), the ingredients, the formulation recipe, the dough final moisture content, and also thermal processing (baking temperature and time) play an important role (Claus et al., 2008, Capuano et al., 2009, Przygodzka et al., 2015, Negoiță et al., 2017a). In the last years, consumers demand for healthier products lead to the use of pseudo-cereals in the recipe, which are either mixed with traditional cereals or are used to replace them totally. From the nutritional point of view, the final product is better than the traditional one but concerns are raised regarding the AA content. In case of cereal-based products, free asparagine 
is the determinant factor of AA formation. Žilić et al. (2020) studied the effect of various wholegrain flours with different content of free asparagine on the AA content of biscuits baked at different condition and showed that the AA level of the final products is correlated with the initial asparagine content of the cereal flours used and the baking time. Compared with refined wheat flour, when the wholegrain bread wheat flour was used, the AA content increased by 65,76 and $89 \%$ for biscuits baked at $180^{\circ} \mathrm{C}$ for 7,10 and $13 \mathrm{~min}$, respectively. Similar results were obtained by Mesías et al. (2019) who showed that wholegrain biscuits had an AA content higher with nearly $50 \%$ compared to refined cereal biscuits.

By analysing 71 different cereal-based products, Nematollahi et al. (2019) concluded that the AA level is dependent on the type of raw material and ingredients used, formulation recipe and baking parameters. The results showed that the AA content ranged between 76.68 to $583.60 \mu \mathrm{g} / \mathrm{kg}$, with the highest average amount found for wafer $(233.94 \mu \mathrm{g} / \mathrm{kg})$.

Very little information about the AA level of Romanian commercialized food and the population exposure to this contaminant is known. Taking this into consideration, the aim of this paper was to realize an overview of AA levels in cereal-based products commercialized on the Romania market between the years 2018 and 2019. These products, due to their relatively widespread consumption, could be a key source of AA in the Romanian diet.

\section{Materials and methods}

\section{Food samples}

A total of 46 samples of cereal-based products found on the Romanian market from which 19 samples are in the bread category, 13 samples in the biscuits and wafers group, 6 samples in the crackers category and 8 samples are products similar to those mentioned were analysed for the AA content. These food products were analysed between the years 2018 and 2019, 35 samples being analysed in 2018, and 11 samples in 2019.

The soft bread samples were sliced, cut into small pieces and then dried at a temperature of $50^{\circ} \mathrm{C}$, for 3 hours in a drying and heating chamber (Binder $\mathrm{GmbH}$, Germany). Before and after drying the bread, the moisture content was determined using a moisture analyzer (Mettler Toledo, China). The samples of dried bread, biscuits with and without cream and other similar products were milled and homogenized in a laboratory mixer (Büchi B-400, BÜCHI Labortechnik AG, Switzerland). From the milled and homogenized samples, $3 \mathrm{~g}$ of bread sample and $1.5 \mathrm{~g}$ of biscuits and other similar products samples, respectively was weighed using an analytical balance to the nearest $0.1 \mathrm{mg}$ (Precisa Gravimetrics AG, Switzerland). The samples were subjected to analysis for the determination of acrylamide content by GC-MS/MS.

\section{Reagents and reference standards}

Native AA of concentration $1004 \mu \mathrm{g} / \mathrm{mL}$ in methanol (99\% purity) was purchased from Restek (Benner Circle, Bellefonte, U.S.) and labelled acrylamide $\left(1,2,3-{ }^{13} \mathrm{C}\right.$ 
labelled AA) (99\% purity) of concentration $1000 \mu \mathrm{g} / \mathrm{mL}$ in methanol $(+100 \mathrm{ppm}$ hydroquinone) used as internal standard (IS) was acquired from Cambridge Isotope Laboratories (Andover, MA, USA). All solvents and reagents were of analytical grade, special for chromatography and were purchased from Merck (Darmstadt, Germany), LGC Promochem GmbH (Wesel, Germany), Alfa Aesar (Thermo Fisher Scientific, USA). Ultrapure water was obtained through a PURELAB Option-S7 and PURELAB Ultra Ionic system (Elga Labwater, High Wycombe, UK).

To assess the quality control, a certified reference material "acrylamide in rusk" $\left(\mathrm{ERM}^{\circledR}\right.$-BD274, BAM, Berlin, Germany) with the certified value of $74 \mu \mathrm{g} / \mathrm{kg}$ was used.

\section{Preparation of reference solutions}

Stock solutions of AA and IS $(100 \mathrm{mg} / \mathrm{L})$ were prepared in ultrapure water in amber vials. Working solutions of AA of concentration 10,1 and $0.1 \mathrm{mg} / \mathrm{L}$, respectively, and working solution of IS of concentration $10 \mathrm{mg} / \mathrm{L}$ were prepared from the stock solutions by dissolving in ultrapure water.

\section{Preparation of calibration solutions}

The calibration solutions were prepared according to the procedure described in a previous study (Negoiță and Culețu, 2016). Two calibration curves were realized in the range of $0.025-5 \mathrm{mg} / \mathrm{L}$ based on the derivatized standard solutions and plotting the ratio of the peak area of 2-bromopropenamide (2-BPA) and 2-BP $\left({ }^{13} \mathrm{C}\right) \mathrm{A}$ against the concentration of 2-BPA.

\section{Acrylamide determination}

Acrylamide analyses were realized on a gas chromatograph, type TRACE GC Ultra, coupled with triple quadrupole mass spectrometer (TSQ Quantum XLS) from Thermo Fisher Scientific (USA). A capillary column based on polyethyleneglycol, TraceGOLD ${ }^{\mathrm{TM}}$ TG-WaxMS $(30 \mathrm{~m} \times 0.25 \mathrm{~mm}$ i.d. $\times 0.25 \mu \mathrm{m}$, Thermo Fisher Scientific, USA) was used as stationary phase. The mobile phase was helium.

The analyses were performed in the electron impact ionization operation mode, positive ( $\left.{ }^{+} \mathrm{EI}\right)$; acquisition mode: selected reaction monitoring (SRM) and ion scanning mode - Product ("Product").

AA analysis was performed according to the method described by Negoiță and Culețu (2016). Briefly, the following steps were followed: samples were milled and homogenized in a Büchi professional mixer, AA was extracted in water and IS was added. Samples were treated with Carrez solutions for deproteinization, and then it was centrifugated. For derivatization the bromine compounds were used and the derivatized compound 2,3-dibromopropanamide (2,3-DBPA) obtained was extracted in a mixture of ethyl acetate: hexane and after that it was concentrated in 2 steps, first with a vacuum evaporation system $\left(40^{\circ} \mathrm{C}, 156-90 \mathrm{mBar}\right)$, and then to dryness under a nitrogen stream. The clean-up was realized on a florisil column, and the 2,3-DBPA derivative was eluted with acetone, concentrated till dryness and 
the residue was redissolved in ethyl acetate and triethylamine. The final extract of 2-BPA was injected to GC-MS/MS.

AA quantification was performed by the internal standard method.

\section{Method performance}

The method used for acrylamide quantification in bread, biscuits and other bakery products was described by Negoiță and Culețu (2016). The recovery of the procedure was in the range of $97 \%-105 \%$. The relative standard deviations for precision, repeatability and reproducibility were $0.4-4.9 \%$ and $0.7-5.8 \%$, respectively.

The Commission Regulation (EU) 2017/2158 states that the method used for the analysis of AA must comply with the following criteria: LOQ less than or equal to two fifths of the benchmark level (for benchmark level $<125 \mu \mathrm{g} / \mathrm{kg}$ ) and less $\leq 50$ $\mu \mathrm{g} / \mathrm{kg}$ (for benchmark level $\geq 125 \mu \mathrm{g} / \mathrm{kg}$ ), while LOD $\leq 3 / 10$ of LOQ (Tabel 1). The analytical method used was characterized by a good sensitivity, with a LOD of $1.23 \mu \mathrm{g} / \mathrm{kg}$, and a LOQ of $3.7 \mu \mathrm{g} / \mathrm{kg}$ for cereal-based products, clearly meeting the required conditions.

According to the same Regulation, the benchmark level for the presence of AA in cereal-based food products are presented in Table 1.

Table 1. Benchmark levels for the presence of acrylamide in cereal-based products and method sensitivity set by Commission Regulation (EU) 2017/2158.

\begin{tabular}{|c|c|c|c|}
\hline \multirow[t]{2}{*}{ Foodstuffs } & \multirow{2}{*}{$\begin{array}{c}\mathrm{BL}^{*} \\
(\mu \mathrm{g} / \mathrm{kg})\end{array}$} & \multicolumn{2}{|c|}{ Sensitivity } \\
\hline & & $\begin{array}{l}\text { LOD } \\
(\mu \mathrm{g} / \mathrm{kg})\end{array}$ & $\begin{array}{c}\text { LOQ } \\
(\mu \mathrm{g} / \mathrm{kg})\end{array}$ \\
\hline \multicolumn{4}{|l|}{ Soft bread } \\
\hline - Wheat based bread & 50 & & $<2 / 5 * \mathrm{BL}$ \\
\hline - Soft bread other than wheat-based bread & 100 & $\leq 3 / 10^{\circ} \mathrm{LOQ}$ & \\
\hline Biscuits and wafers & 350 & & \\
\hline $\begin{array}{l}\text { Crackers with the exception of potato-based } \\
\text { crackers }\end{array}$ & 400 & $\leq 3 / 10 *$ LOQ & $\leq 50$ \\
\hline $\begin{array}{l}\text { Products similar to the other products in this } \\
\text { category (fine bakery products) }\end{array}$ & 300 & & \\
\hline
\end{tabular}

*Acrylamide benchmark levels (BL)

The accuracy of the results was demonstrated for cereal-based matrix (biscuitcookie) by participation to two proficiency tests (PT) launched by the Food Analysis Performance Assessment Scheme (FAPAS) program, yielding z-scores of -0.2 (PT 3084, 2018) and -0.1 (PT 3094, 2019), respectively. All analyses were performed in duplicate and results were expressed as $\mu \mathrm{g} / \mathrm{kg}$ AA.

\section{Results and discussion}

In order to determine the AA content of cereal-based products, two calibration curves were realized by the method of least squares in the ranges $0.025-0.5 \mathrm{mg} / \mathrm{L}$ (Figure 1) and 0.4- $5 \mathrm{mg} / \mathrm{L}$ (Figure 2) choosing the internal standard method. The 
correlation was assessed to be linear for a value greater than 0.99 for the correlation coefficient $(\mathrm{R})$.

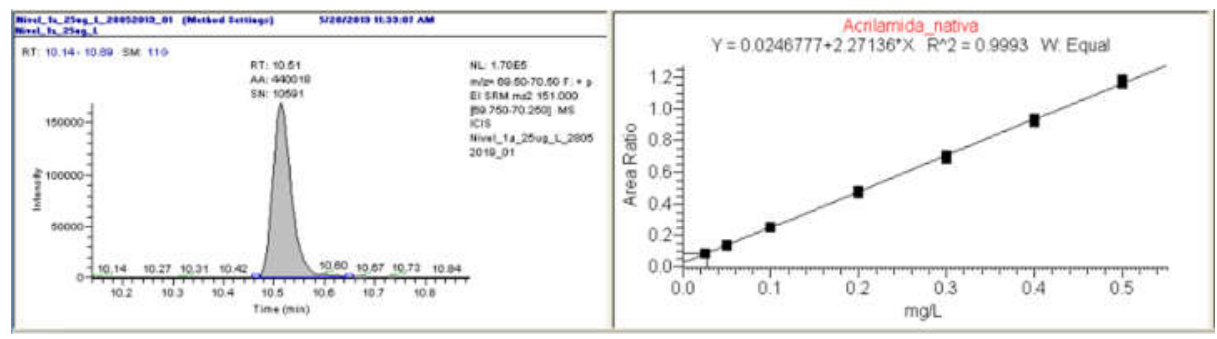

Figure 1. Calibration curve $(0.025-0.5 \mathrm{mg} / \mathrm{L})$ for acrylamide (2-BPA) detection analysis and acrylamide peak

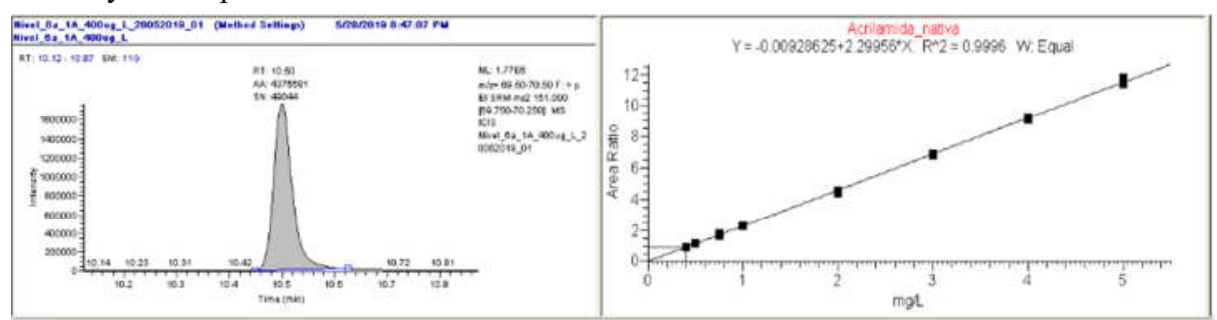

Figure 2. Calibration curve $(0.4-5 \mathrm{mg} / \mathrm{L})$ for acrylamide (2-BPA) detection analysis and acrylamide peak

Quality control (QC) in the laboratory (Figure 3) was performed with each set of samples analyzed using a certified reference material "acrylamide in rusk", and the bias obtained was $0.58 \%(n=33)$.

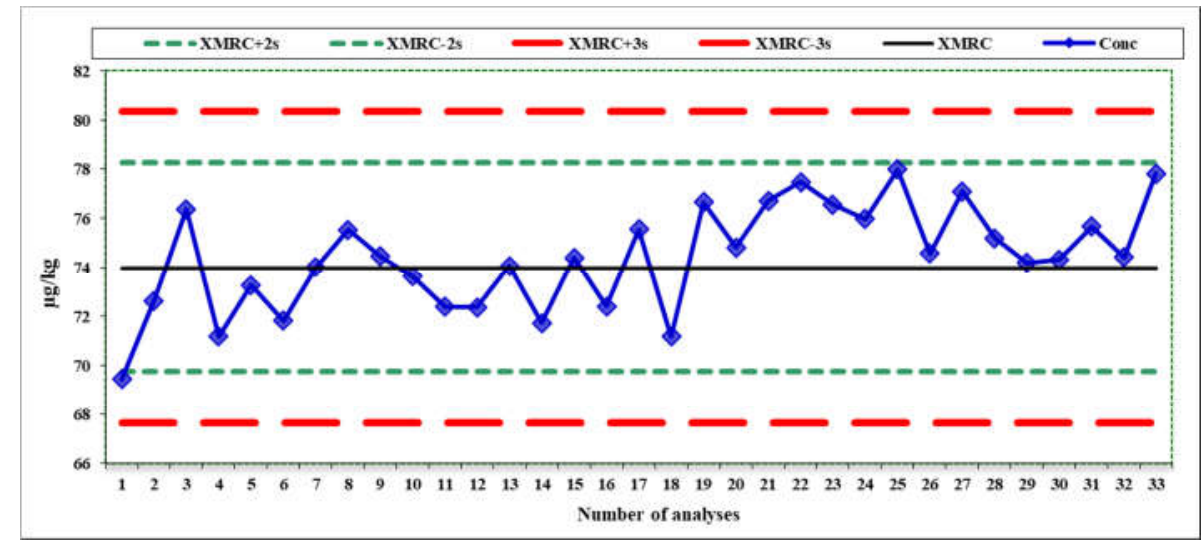

Figure 3. Quality control chart for the determination of acrylamide in the QC samples

The results obtained by analyzing the samples showed that the AA content between the same category of food and between groups varied. It is well known that the AA 
formation depends on the asparagine and reducing sugars content of the raw materials, as well as the processing conditions.

\section{AA content of soft bread}

Bread is one of the most consumed cereal-based products in Romanian diet, Romania being one of the top three bread consuming countries in Europe (FRD, 2016).

A total of 19 commercial bread samples of which 14 samples were from the wheatbased bread category, and 5 samples were from the soft bread other than wheatbased bread group were analysed for the AA content (Table 2).

In the bread samples obtained from wheat, the AA content varied between 5.63 and $45.01 \mu \mathrm{g} / \mathrm{kg}$, while for bread obtained from other cereals the AA content varied between 21.78 and $85.05 \mu \mathrm{g} / \mathrm{kg}$.

Table 2. Acrylamide content of bread samples analysed.

\begin{tabular}{lll}
\hline No. & Bread & AA content, $\boldsymbol{\mu g} / \mathbf{k g *}$ \\
\hline \multicolumn{3}{c}{ Wheat-based bread } \\
\hline 1 & Classic toast & $8.53 \pm 0.44$ \\
2 & Mini bread baguette with sesame & $19.29 \pm 1.18$ \\
3 & Whole toast & $8.28 \pm 0.69$ \\
4 & Hot-dog roll & $12.24 \pm 0.44$ \\
5 & Wheat bun & $28.08 \pm 0.26$ \\
6 & Peasant bread & $9.79 \pm 0.05$ \\
7 & Sliced Classic white loaf bread & $5.63 \pm 0.22$ \\
8 & Wheat bread & $7.11 \pm 0.32$ \\
9 & Graham toast & $16.91 \pm 0.62$ \\
10 & Sliced wheat bread & $9.34 \pm 0.98$ \\
11 & Wheat bread & $6.79 \pm 0.15$ \\
12 & Lebanese bread 1 & $45.01 \pm 2.04$ \\
13 & Lebanese bread 2 & $30.94 \pm 1.56$ \\
14 & Lebanese bread 3 & $31.54 \pm 0.27$ \\
\hline \multicolumn{3}{c}{ Soft bread other than wheat-based bread } \\
\hline 1 & Bread made of rye MIX & $36.56 \pm 0.11$ \\
2 & Bread made with rye (rye -potato) & $35.86 \pm 0.17$ \\
3 & Rye bread & $85.05 \pm 0.10$ \\
4 & Bread with fibre and seeds & $74.17 \pm 0.49$ \\
5 & Rye bread toast & $21.78 \pm 1.49$ \\
\hline
\end{tabular}

* Data are expressed as mean values \pm standard deviations (SDs) of two replicates

Three samples of Lebanese bread from the same brand were analysed between 2018 and 2019, of which one was analysed in 2018 and presented the highest level of AA from the wheat bread category $(45.01 \mu \mathrm{g} / \mathrm{kg})$, and the other two were analysed in 2019. As it can be noticed from Table 2, the AA content of this product 
decreased in 2019 with about $30 \%$ as a result of the mitigation measures applied by the food business operator in order to reduce AA formation in this product.

From all of the soft bread analysed, the highest AA content was obtained for ryebread. The type of cereal used in the formulation recipe of bread is a factor which influences the AA level. In some bread model systems realized by Capuano et al. (2009) it was demonstrated that the flour type has a determinant effect on the AA content, higher levels being obtained when in the recipe rye flour is used, followed by whole wheat and wheat flours. Similar results were obtained by Przygodzka et al. (2015) who showed that the cereal from which the flour is obtained has implication on the AA level of bread, the highest level being found in rye bread compared to wheat and spelt breads.

Forstova et al. (2014) studied the AA content of bread produced in various Czech bakeries and, as in our study, the level was low, ranging between 7 and $22 \mu \mathrm{g} / \mathrm{kg}$. The content of AA detected in the bakery products analysed in Romania were similar with the ones measure in Lesser Poland, where the level was between undetectable to $77.7 \mu \mathrm{g} / \mathrm{kg}$, with an average of $29.74 \mu \mathrm{g} / \mathrm{kg}$ for the 15 products analysed (Cieślik et al., 2019). In a survey carried out in Iran, the AA values of traditional and industrial bread samples were less than $83.3 \mu \mathrm{g} / \mathrm{kg}$ (Eslamizad et al., 2019).

The AA levels for all bread samples analysed were below the benchmark levels presented in the Commission Regulation (EU) 2017/2158.

Soft bread contributes to AA exposure to adults in a percent of $23 \%$, followed by biscuits, crackers and crisp bread (EFSA, 2015). Adult chronic dietary exposure to AA estimated by EFSA was between 0.4 and $0.9 \mu \mathrm{g} / \mathrm{kg}$ b.w./day. Exposure to AA from bread in the Romanian population was estimated considering total data per capita consumption of this product of $95 \mathrm{~kg} /$ capita/year as indicated by FRD (2016). Taking into account that in Romania, the bread intake for an adult weighing $80 \mathrm{~kg}$ is $260 \mathrm{~g} /$ day (FRD, 2016), and based on the average level of AA from bread obtained in this study (average of $25.99 \mu \mathrm{g} / \mathrm{kg}$, Table 2), it can be concluded that bread contributes to a chronic dietary exposure of $0.9 \mu \mathrm{g} / \mathrm{kg}$ b.w./day with about $9.37 \%$. In Poland, similar as in Romania, bakery products are very consumed and they are the main source of AA. In the study realized by Cieślik et al. (2019) the mean AA exposure from the consumption of bread ranged between 0.01 and $0.05 \mu \mathrm{g} / \mathrm{kg}$ b.w./day, the AA exposure decreasing with increasing age. When evaluating the dietary exposure to AA of Slovenian adult population, Mencic et al. (2020) calculated an average dietary exposure to AA of toast and bread products of $0.21 \mu \mathrm{g} / \mathrm{kg}$ b.w./day, these foodstuffs contributing with $56 \%$ to dietary exposure to AA. In France, the estimated dietary exposure to AA among children and adults was 0.020 , and $0.024 \mu \mathrm{g} / \mathrm{kg}$ b.w./day, respectively when bread and bread products were consumed (Sirot et al., 2012).

\section{AA content of biscuits and wafers}

Biscuits are a cereal-based food product which include sugars and fats in their composition. Sugar is one of the main ingredients in the recipe and at high 
temperatures it participates to the Maillard reaction, thus influencing the AA content of the end product. The difference in biscuits composition and in the processing conditions applied can easily explain the observed variability between samples. Studies showed that AA formation is dependent on the type and concentration of sugars and revealed that fructose contribute to the formation of a higher level of AA compared to glucose (Mustățea et al., 2015, Nguyen et al., 2016, Nguyen et al., 2017). Also, the type of fat and wheat flour used influences the AA level of biscuits (Negoiță et al., 2017b).

On Romanian market, the most consumed biscuits are cream "sandwich" biscuits, followed by simple biscuits (FRD, 2016). Due to the high rate of consumption, biscuits are an important source of AA intake. Out of the biscuits and wafers category, a total of 13 samples were analysed to determine the AA content (Table 3).

Table 3 Acrylamide content of biscuits and wafers samples analysed.

\begin{tabular}{lll}
\hline No. & Biscuits and wafers & $\begin{array}{c}\text { AA content, } \\
\boldsymbol{\mu g} / \mathbf{k g}\end{array}$ \\
\hline 1 & Double-biscuits with cacao cream & $548.80 \pm 16.53$ \\
2 & Mini-biscuits with cacao flavour & $278.53 \pm 0.46$ \\
3 & Cacao biscuits with cacao cream & $207.23 \pm 0.14$ \\
4 & Mini-cacao biscuits with cacao cream & $275.33 \pm 2.73$ \\
5 & Cacao biscuits with cacao cream & $255.83 \pm 3.47$ \\
6 & Mini-cacao biscuits with vanilla flavoured cream & $165.30 \pm 1.29$ \\
7 & Biscuits with honey & $304.87 \pm 7.93$ \\
8 & Mini-biscuits with cacao cream & $426.03 \pm 2.43$ \\
9 & Sweet biscuits 1 & $538.26 \pm 15.90$ \\
10 & Sweet biscuits 2 & $538.95 \pm 4.22$ \\
11 & Sweet biscuits 3 & $166.97 \pm 9.36$ \\
12 & Cookies & $8.55 \pm 0.04$ \\
13 & Éclair shells & $29.45 \pm 2.32$ \\
\hline
\end{tabular}

*Data are expressed as mean values \pm standard deviations (SDs) of two replicates

For this group of cereal-based products, 4 samples analysed between 2018 and 2019 exceeded the benchmark level of $350 \mu \mathrm{g} / \mathrm{kg}$ established by Regulation 2017/2158. The highest AA content was recorded for double-biscuits with cacao cream $(548.80 \mu \mathrm{g} / \mathrm{kg})$, followed by 2 samples of sweet biscuits $(1-538.26 \mu \mathrm{g} / \mathrm{kg}$ and 2- $538.95 \mu \mathrm{g} / \mathrm{kg})$ and mini-biscuits with cacao cream $(426.03 \mu \mathrm{g} / \mathrm{kg})$. The sweet biscuits (1 and 2) for which it was determined a higher AA content than the one set out for Commission Regulation (EU) 2017/2158 were analysed in 2018. It can be noticed that for this sample analysed in 2019 the AA content decreased by about $70 \%$ as a result of the mitigation measures applied by food business operators.

From the wafers group, cookies and éclair shells were analysed and an AA level less than $30 \mu \mathrm{g} / \mathrm{kg}$ was detected. 
From the biscuits and wafers category analysed, $31 \%$ of the tested samples exceeded the benchmark level of Regulation 2158/2017. Michalak et al. (2019) investigated the AA level of food products purchased from the Poland supermarkets and in the case of biscuits, the AA content was exceeded for all ten samples analysed, the mean AA content being higher with $49 \%$ than the benchmark level. In a study realized by Tölgyesi and Sharma (2020) on 42 biscuits samples purchased from Hungary shops it was shown that the AA level ranged between 20 and $342 \mu \mathrm{g} / \mathrm{kg}$, being less than the one set by legislation. When comparing the AA content of Spanish biscuits marked on 2007 versus 2019, it was noticed that an important decline of $45 \%$ was obtained for wheat-based biscuits as a result of the mitigation strategies applied by the biscuit manufacturers (Mesías et al., 2019). To estimate the exposure to AA from biscuits intake in the Romanian population was taken into account the amount of $2.1 \mathrm{~kg} / \mathrm{capita} / \mathrm{year}$ as indicated by FRD (2016). Considering that in Romania, the biscuits and similar products intake for an adult weighing $80 \mathrm{~kg}$ is $6.03 \mathrm{~g}$ /day (FRD, 2016) and based on the average level of AA obtained in this study for the biscuits (average of $288.01 \mu \mathrm{g} / \mathrm{kg}$, Table 3 ), it can be concluded that biscuits contributes to a chronic dietary exposure of 0.9 $\mu \mathrm{g} / \mathrm{kg}$ b.w./day with about $2.40 \%$. In a study realized in Slovenia, the dietary exposure to AA by consumption of biscuits and wafers ranged between 0.03 and $0.04 \mu \mathrm{g} / \mathrm{kg} \mathrm{b.w}$./day, these products contributing with $9 \%$ of the dietary exposure to AA of adult population (Mencic et al., 2020). In France, the estimated dietary exposure to AA by consumption of sweet biscuits was $0.017 \mu \mathrm{g} / \mathrm{kg}$ b.w./day for adults, while for children was $0.075 \mu \mathrm{g} / \mathrm{kg} \mathrm{b} . \mathrm{w} . /$ day (Sirot et al., 2012).

\section{AA content of crackers}

In Romania, from the salty snacks category, the most consumed products are pretzels, followed by crackers and a less percent of sticks, mixes and salty sticks (FRD, 2016).

A total of 6 samples from the crackers category were analysed for AA content determination (Table 4). The benchmark level for this category is set to $400 \mu \mathrm{g} / \mathrm{kg}$ (Regulation 2017/2158) and none of the analysed samples did not exceeded this level, the AA content varying between 13.92 and $167.58 \mu \mathrm{g} / \mathrm{kg}$. It is known that the difference in the food composition and in the processing parameters applied influence the AA content, the highest values being found in crackers in which just salt was added, compared to the ones where another ingredient was added.

Table 4 Acrylamide content of crackers samples analysed.

\begin{tabular}{lll}
\hline No. & Crackers & AA content, $\boldsymbol{\mu g} / \mathbf{k g *}$ \\
\hline 1 & Rusk & $13.92 \pm 0.43$ \\
2 & Pretzels with white wine & $73.84 \pm 3.86$ \\
3 & Pretzels with salt and cumin & $59.69 \pm 2.99$ \\
4 & Pretzels with salt and poppy seeds & $81.00 \pm 1.42$ \\
5 & Pretzels with salt & $167.58 \pm 2.24$ \\
6 & Mini brezel salt & $111.73 \pm 2.03$ \\
\hline
\end{tabular}

*Data are expressed as mean values \pm standard deviations (SDs) of two replicates 
Similar results were obtained by Cieślik et al. (2019) and Nematollahi et al. (2019) who found for pretzels an AA content ranging from 69.3 to $124 \mu \mathrm{g} / \mathrm{kg}$, and 126.90 $\mu \mathrm{g} / \mathrm{kg}$, respectively. Higher AA levels were found in the survey conducted by Gündüz et al. (2017) where the mean AA content for crackers was $604 \mu \mathrm{g} / \mathrm{kg}$.

\section{AA content of fine bakery products}

The AA level of fine bakery products was evaluated as well on 8 samples. As it can be noticed from Table 5, none of the analysed samples from this category did not exceed the benchmark level of $300 \mu \mathrm{g} / \mathrm{kg}$ set out by European Commission 2017/2158. In the fine bakery composition, the addition of sugar or similar ingredients can affect the AA level of end product. For sponge cake an AA level of $16.67 \mu \mathrm{g} / \mathrm{kg}$ was found in our study, while Nematollahi et al. (2019) found for the same product commercialized on Iran market an average content of $148.33 \mu \mathrm{g} / \mathrm{kg}$.

Table 5 Acrylamide content of fine bakery samples analysed.

\begin{tabular}{lll}
\hline No. & Fine bakery & AA content, $\boldsymbol{\mu g} / \mathbf{k g *}$ \\
\hline 1 & White cake & $12.93 \pm 0.47$ \\
2 & Rum baba & $12.57 \pm 0.11$ \\
3 & Amandine & $15.02 \pm 0.94$ \\
4 & Sponge cake & $16.67 \pm 0.53$ \\
5 & Cremeschnitte & $99.01 \pm 6.72$ \\
6 & Marble cake without fruit & $30.96 \pm 1.32$ \\
7 & Marble cake & $29.45 \pm 2.32$ \\
8 & Doughnuts & $27.87 \pm 0.20$ \\
\hline
\end{tabular}

*Data are expressed as mean values \pm standard deviations (SDs) of two replicates

In this category of food products, the highest AA content was obtained in cremeschnitte sample $(99.01 \mu \mathrm{g} / \mathrm{kg})$, the other products analysed having a level ranging between 12.57 and $30.96 \mu \mathrm{g} / \mathrm{kg}$. In a survey realized by Razia et al. (2016), similar results were obtained for cakes, the AA level being less than $35 \mu \mathrm{g} / \mathrm{kg}$.

\section{Conclusions}

AA was present in all samples analyzed, this indicating that cereal-based products contribute to AA intake as are daily consumed. From the total of 46 samples, AA was detected in all cereal-based products analyzed between 2018 and 2019 at levels ranging from $5.63 \mu \mathrm{g} / \mathrm{kg}$ to $548.80 \mu \mathrm{g} / \mathrm{kg}$.

Of all the analyzed samples (46), only $8.7 \%$ (4) exceeded the level of AA established by Regulation (EU) 2017/2158. The highest AA content was found in biscuits, like this contributing to AA exposure.

Mitigation strategies should be applied to reduce the AA formation in all cereal based-products, not only in biscuits, thus reducing the AA exposure among the population. It is important to have a balanced healthy diet in which the consumption of bakery products to be limited. 


\section{Acknowledgments}

This study was achieved through Core Programme (PN 19 02), with the support of the Ministry of Research and Innovation (MCI), contract 22N/2019, project PN 19 020301 .

\section{References}

AL Karim, S., El Assouli, S., Ali, S., Ayuob, N., El Assouli, Z. 2015. Effects of low dose acrylamide on the rat reproductive organs structure, fertility and gene integrity. Asian Pacific Journal of Reproduction, 4(3), 179-187.

Capuano, E., Ferrigno, A., Acampa, I., Serpen, A., Açar, Ö., Gökmen, V., Fogliano, V. 2009. Effect of flour type on Maillard reaction and acrylamide formation during toasting of bread crisp model systems and mitigation strategies. Food Research International, 42, 1295-1302.

Cieślik, I., Cieslik, E., Topolska, K., Surma, M. 2019. Dietary acrylamide exposure from traditional food products in Lesser Poland and associated risk assessment. Annals of Agricultural and Environmental Medicine: AAEM, 27(2), 225-230.

Claus, A., Mongili, M., Weisz, G., Schieber, A., Carle, R., 2008. Impact of formulation and technological factors on the acrylamide content of wheat bread and bread rolls. Journal of Cereal Science, 47, 546-554.

Eslamizad, S., Kobarfard, F., Tstsimpikou, C., Tsatsakis, A., Tabib, K., Yazdanpanah, H. 2019. Health risk assessment of acrylamide in bread in Iran using LC-MS/MS. Food and Chemical Toxicology, 126, 162-168.

European Commission (EU). 2017. Commission Regulation 2017/2158 of 20 November 2017 establishing mitigation measures and benchmark levels for the reduction of the presence of acrylamide in food. Official Journal of the European Union, L304, 24-44.

European Food Safety Authority (EFSA). 2015. Scientific opinion on acrylamide in food. EFSA Panel on contaminants in the food chain (CONTAM). EFSA Journal, 13(6), 4104.

Food Drink Europe. 2019. Acrylamide toolbox. Available from: https://www.fooddrinkeurope.eu/uploads/publications_documents/FoodDrinkEurope_A crylamide_Toolbox_2019.pdf.

FRD. 2016. Food market in Romania. A FRD Center publication for the Embassy of the Kingdom of the Netherlands in Romania, available from: https://www.dutchromaniannetwork.nl/wp-content/uploads/2017/01/Food-ReportRomania-2016.pdf.

Forstova, V., Belkova, B., Riddellova, K., Vaclavik, L., Prihoda, J., Hajslova, J. 2014. Acrylamide formation in traditional Czech leavened wheat-rye breads and wheat rolls, Food Control, 38, 221-226.

Gündüz, C.P.B., Bilgin, A.K., Cengiz, M.F. 2017. Acrylamide contents of some commercial crackers, biscuits and baby biscuits. Akademik Gida, 15(1), 1-7.

International Agency for Research on Cancer (IARC). 1994. Monographs on the Evaluation of Carcinogenic Risks of Chemicals to Humans, 60, 389, Lyon, France.

FAO/WHO. 2011. Evaluation of certain contaminants in food: Seventy-second report of the Joint FAO/WHO Expert Committee on Food Additives, Rome. 
Kacar, S., Sahinturk, V., Mehtap, K. 2019. Effect of acrylamide on BEAS-2B normal human lung cells: Cytotoxic, oxidative, apoptotic and morphometric analysis. Acta Histochemica, 121, 595-603.

Matoso, V., Bargi-Souza, P., Ivanski, F., Romano, M.A., Romano, R.M. 2019. Acrylamide: A review about its toxic effects in the light of developmental origin of health and disease (DOHaD) concept. Food Chemistry, 283, 422-430.

Mencin, M., Abramovič, H., Vidrih, R., Schreiner, M. 2020. Acrylamide levels in food products on the Slovenian market, Food Control, 107267.

Mesías, M., Morales, F.J., Delgado-Andrade, C. 2019. Acrylamide in biscuits commercialized in Spain: a view of the Spanish market from 2007 to 2019. Food \& Function, 10, 6624-6632.

Michalak, J., Czarnowska-Kujawska, M., Gujska, E. 2019. Acrylamide and thermalprocessing indexes in market-purchased food. International Journal of Environmental Research and Public Health, 16, 4724, 1-9.

Mustățea, G., Popa, M.E., Negoiță, M., Israel Roming, F. 2015. Asparagine and sweeteners - how they influence acrylamide formation in wheat flour biscuits? Abstracts/Journal of Biotechnology, 208, S5-S120.

Negoiță, M., Culețu, A., 2016. Application of an accurate and validated method for identification and quantification of acrylamide in bread, biscuits and other bakery products using GC-MS/MS system. Journal of Brazilian Chemical Society, 27(10), 1782-1791.

Negoiță, M., Mihai, A.L., Iorga, E., 2017a. Influence of technological factors on acrylamide level from biscuits. Scientific Bulletin. Series F. Biotechnologies, XXI, 149-158.

Negoiță, M., Iorga, E., Mihai, A.L., Spadaro, G., 2017b. Investigation regarding the influence of certain types of fat content on acrylamide level in biscuits. Journal of Hygienic Engineering and Design, 15, 31-41.

Nematollahi, A., Kamankesh, M., Hosseini, H., Ghasemi, J., Hosseini-Esfahani, F., Mohammadi, A. 2019. Investigation and determination of acrylamide in the main group of cereal products using advanced microextraction method coupled with gas chromatography-mass spectrometry. Journal of Cereal Science, 87, 157-164.

Nguyen, Ha T., Van der Fels-Klerx, H.J. (Ine)., Peters, R.J.B., Van Boekel, M.A.J.S. 2016. Acrylamide and 5-hydroxymethylfurfural formation during biscuit baking: Part I: Effect of sugar type, Food Chemistry, 192, 575-585.

Nguyen, Ha T., Van der Fels-Klerx, H.J. (Ine)., Van Boekel, M.A.J.S. 2017. Acrylamide and 5-hydroxymethylfurfural formation during biscuit baking. Part II: Effect of the ratio of reducing sugars and asparagine, Food Chemistry, 230, 14-23.

Przygodzka, M., Piskula, M.K., Kukurová, K., Ciesarová, Z., Bednarikova, A., Zieliński, H. 2015. Factors influencing acrylamide formation in rye, wheat and spelt breads, Journal of Cereal Science, 65, 96-102.

Razia, S., Bertrand, M., Klaus, V., Meinolf, G.L. 2016. Investigation of acrylamide levels in branded biscuits, cakes and potato chips commonly consumed in Pakistan. International Food Research Journal, 23(5), 2187-2192.

Sirot, V., Hommet F., Tard, A., Leblanc, J.-C. 2012. Dietary acrylamide exposure of the French population: Results of the second French Total Diet Study, Food and Chemical Toxicology, 50, 889-894. 
Tölgyesi, Á., Sharm, V.K. 2020. Determination of acrylamide in gingerbread and other food samples by HILIC-MS/MS: A dilute-and-shoot method. Journal of Chromatography B, 1136, 121933.

Žilić, S., Aktağ, I.G., Dodig, D., Filipović, M., Gökmen, V., 2020. Acrylamide formation in biscuits made of different wholegrain flours depending on their free asparagine content and baking conditions. Food Research International, 132, 109109 